\title{
ANÁLISE MOLECULAR DE PROTOZOÁRIOS DA FAMÍLIA SARCOCYSTIDAE EM AMOSTRAS TECIDUAIS DE ÓRGÃOS DE OVINOS NO MUNICÍPIO DE FEIRA DE SANTANA, BA
}

\author{
Taise Cristina Santa Barbara Silva Queiroz ${ }^{1}$; Caroline Araújo da Silva ${ }^{2}$; Aline Moraes \\ Bergossi Gomes ${ }^{3}$; Joelande Esquivel Correa ${ }^{3}$; Jadson Nascimento Borges ${ }^{4}$; Luciara \\ Alves da $\mathrm{Cruz}^{3}$; Kathleen de Almeida Ferreira ${ }^{4}$; Aristeu Vieira da Silva ${ }^{3,5}$ \\ 1. Bolsista PIBIC/FAPESB, Graduando em Bacharelado em Ciências Biológicas, Universidade Estadual de Feira de \\ Santana - UEFS, taii.cristina@ hotmail.com \\ 2. Bolsista PIBIC/FAPESB, Graduando em Bacharelado em Ciências Biológicas, UEFS, carol.adp@ @otmail.com \\ 3.Grupo de Pesquisa em Zoonoses e Saúde Pública - GPZSP/UEFS, alinemoraesx@ gmail.com, joelandecorreia@ gmail.com, \\ luciara@uefs.br \\ 4. . Bolsista PIBIC/CNPq, Graduandos em Bacharelado em Ciências Biológicas, UEFS, jadsonnascimento1@ hotmail.com, \\ kathleen_fsa@hotmail.com \\ 5. GPZSP/UEFS, orientador, aristeuvsilva@uefs.br
}

PALAVRAS-CHAVE: Sarcocystidae; molecular; ovinos.

\section{INTRODUÇÃO}

A família Sarcocystidae (Filo Apicomplexa) abrange os protozoários heteróxenos (REY, 2001), com a capacidade de formar cistos teciduais em hospedeiros intermediários (MUGRIDGE et al., 1999). A família Sarcocystidae é composta pelos gêneros Sarcocystis, Frenkelia, Toxoplasma, Hammondia, Besnoitia e Neospora (REY, 2001; MUGRIDGE et al., 1999), que exibem significativa importância médica, veterinária e econômica (MUGRIDGE et al., 1999), podendo causar abortamento em animais, e assim proporcionar prejuízos significativos ao comércio de ovinos em diversas regiões do mundo (GUTIERREZ et al., 2010; DEHAGHI et al., 2013; SILVA et al. 2013; KOLENDA et al. 2014).

$\mathrm{Na}$ perspectiva de gerar informações para reduzir a contaminação de produtos pecuários por protozoários, o primeiro passo é notificar a prevalência desses parasitos (FUKUYO et al., 2002). O diagnóstico baseado na sorologia e clínica nem sempre é possível (SWITAJ et al., 2005). Ademais, através da comparação entre Toxoplasma, Neospora, Sarcocystis e Hammondia, os cientistas indicaram que a microscopia de luz não é suficiente para um diagnóstico preciso (RASSOULI et al. 2014). Nesse contexto, as técnicas moleculares vêm revolucionado a identificação de microrganismo em diversas áreas de estudo, tal como a parasitologia (VALONES et al., 2009).

A Reação em Cadeia da Polimerase em Tempo Real (qPCR) proporciona um rápido diagnóstico de patógenos, com melhor controle de qualidade e um menor risco de contaminação (VALONES et al., 2009). Devido à importância econômica, clínica e epidemiológica dos parasitos da família Sarcocystidae, objetivou-se no trabalho avaliar a taxa de contaminação de amostras teciduais de órgãos de ovinos (Ovis aries) por protozoários da família Sarcocystidae utilizando a técnica de qPCR pela análise de alta resolução de curvas de dissociação (HRM).

\section{MATERIAL E MÉTODOS}

Foram coletadas 90 amostras teciduais de órgão (baço, fígado e rins) de ovinos (Ovis aries) de mercados públicos de Feira de Santana-BA obtidos de um projeto anterior. Foram pesados $25 \mathrm{~g}$ de cada amostra, que foram triturados e armazenados em erlenmeyer de $250 \mathrm{ml}$, sendo adicionados $125 \mathrm{ml}$ de solução salina $0,18 \%$ estéril para homogeneização, em seguida, $1 \mathrm{ml}$ da suspensão de tecidos foi coletada e armazenados a $-20^{\circ} \mathrm{C}$ para posterior extração de DNA (TAIRA et al., 2011). 
O DNA foi extraído utilizando dois kits comerciais (A e B) e quantificado em NanoDrop ${ }^{\circledR}$, as quais as concentrações de DNA foram ajustadas até $20 \mathrm{ng} / \mu \mathrm{L}$. Depois, realizou-se as reações de qPCR para sequência do gene 18S do rRNA de Sarcocystidae e análise por HRM para diferenciação dos amplicons, em acordo com Fehlberg (2016). Nas reações foram incluídos os controles positivos (DNA extraído de Toxoplasma gondii cepa RH e Sarcocystis neurona cepa 37-R) e negativos (água ultrapura).

\section{RESULTADOS E DISCUSSÃO}

Do total de 90 amostras submetidas à HRM, apenas uma (1,00\%; IC 95\%: 0,03-5,45) apresentou amplificação, apresentando uma curva de dissociação diferente daquela encontrada para os controles. A Tabela 1 apresenta a variação e a média das temperaturas de melting das amostras controle e da única amostra que amplificou na qPCR para detecção do gene $18 \mathrm{~S}$ rRNA de Apicomplexa.

Tabela 1. Média e variação das temperaturas de melting $(\mathrm{Tm})$ dos controles e da amostra amplificada submetidos à qPCR. Feira de Santana, 2016.

\begin{tabular}{cccc}
\hline Amostra & Tipo & Média da Tm $\left({ }^{\mathbf{0}} \mathbf{C}\right)$ & Variação da Tm $\left({ }^{\mathbf{}} \mathbf{C}\right)$ \\
\hline Toxoplasma gondii cepa RH & Controle & 79,2 & $78,2-80,1$ \\
Sarcocystis neurona cepa 37-R & Controle & 77,$9 ; 80,8$ & $77,1-78,6 ; 79,9-81,6$ \\
SP 58 & Amostra & 77,9 & $77,0-78,8$ \\
\hline
\end{tabular}

A amostra tecidual de órgãos do ovino, que amplificou, apresentou resultado de HRM mais compatível com o primeiro pico de amplificação do controle positivo para Sarcocystis neurona do que com o pico de amplificação do controle positivo de Toxoplasma gondii, visto que a variação da temperatura de melting da amostra foi mais similar a primeira variação apresentada pelo controle positivo $S$. neurona, quando comparado a variação que ocorreu no controle de $T$. gondii. Entretanto, amostra não apresentou a segunda variação de temperatura de melting apontada pelo controle.

As frequências absolutas da quantificação do DNA extraído com kit A apresentou médias de extração entre 79,4ng/ $\mu 1$ e $683,4 \mathrm{ng} / \mu 1$. Em relação ao DNA extraído com kit B, a média de extração foi de 3,2 ng/ $\mu$ l. Assim, o kit A mostrou-se mais eficiente que o kit B.

Os resultados negativos para o HRM nas amostras analisadas podem ser explicados por várias hipóteses. Primeiramente, as amostras analisadas na PCR são produto do processamento em conjunto dos tecidos de vários órgãos (baço, fígado e rins), assim, os tecidos que apresentavam baixa quantidade ou nenhuma de parasito pode ter contribuído para diminuição da quantidade total de DNA do parasito. Segundo Piergili (2004), a concentração de cistos pode ser reduzida em função do número de amostras a serem extraídas. Ademais, os cistos ou taquizoítos não estão uniformemente distribuídos nos tecidos e o corpo dos hospedeiros (PIERGILI, 2004; CENCI-GOGA et al., 2011).

Em estudo realizado por Gutierrez et al. (2010) foi possível detectar o DNA de Toxoplasma gondii em diferentes tipos de tecidos, incluindo baço, pulmão, fígado e rim, contudo, a taxa de detecção foi mais alta no cérebro. Em outro trabalho com ovinos foi possível localizar T. gondii no cérebro, pulmão, coração, rim e musculo esquelético, só que o cérebro foi o órgão com maior detecção e maior carga do parasito, enquanto outras estruturas internas como fígado e baço foram negativas (JURÁNKOVÁ et al., 2015). Já Sarcocystis spp. preferem órgãos como coração, diafragma, esôfago e músculos esqueléticos para se instalarem (BUXTON, 1998; DEHAGHI et al., 2013).

Outra hipótese para explicar os resultados negativos no HRM pode ser relacionada limitada sensibilidade da técnica de PCR em determinadas condições. Apesar da alta especificidade da PCR, a sensibilidade da técnica é limitada, por exemplo, por concentrações 
ideais de DNA da amostra, dessa forma, o procedimento utilizado para extração de DNA pode interferir no resultado da PCR (ALFONSO et al., 2009).

O ensaio de PCR pode apresentar capacidade reduzida em detectar amostras positivas (PORTELLA et al., 2016), por exemplo, a quantificação de $T$. gondii pode ser prejudicada na qPCR usando SYBR Green I quando as amostras possuem mais de $200 \mathrm{ng}$ de DNA não específico (BELLETE et al., 2003). Além disso, o método de isolamento do T. gondii de tecidos infectados depende da apresentação de material novo para o laboratório de diagnóstico, bem como a fase de coleta das amostras (ALFONSO et al., 2009; GUTIERREZ et al., 2010). A quantidade de alvo rDNA presente no organismo também depende da fase de esporulação do oocisto e da espécie de oocisto (VARMA et al, 2003).

$\mathrm{O}$ armazenamento prolongado das amostras pode interferir na qualidade do DNA a ser extraído da amostra. Apesar do registro de que os níveis de DNA permaneceram estáveis nas amostras após 16 meses de armazenamento (JERONE et al. 2002), durante as pesquisas laboratoriais as amostras são expostas a ciclos repetidos de congelamento e descongelamento, devido a impossibilidades do processo das amostras logo após sua coleta (BELLETE et al., 2003), esses ciclos de congelamento e descongelamento podem prejudicar a qualidade total de DNA.

Outra suposição a ser revelada é o fato do volume $(1 \mathrm{~mL})$ da suspensão de tecidos utilizado para extração de DNA foi insuficiente para detectar o parasito. Ou as amostras analisadas apresentavam baixa carga parasitária. Segundos alguns autores, a densidade de parasito pode ser muito baixa em algumas situações (PIERGILI, 2004; ALFONSO et al., 2009; CENCI-GOGA et al., 2011), por exemplo, a densidade de T. gondii nos tecidos de animais assintomáticos é baixa, dificultando a detecção direta do parasito a partir dos tecidos (DUBEY et al., 2005). Ou as amostras examinadas no estudo não estavam contaminadas com protozoários apicomplexos.

Existem diferenças entre as temperaturas de dissociação entre os controles e amostra com amplificação. A diferença da temperatura de fusão é provavelmente devida a diferenças no teor em G-C ao longo do comprimento da sequência, além disso, é possível observar vários domínios de fusão distintos dentro amplicons maiores (LALONDE, GAJADHAR, 2011).

\section{CONSIDERAÇÕES FINAIS}

Análise molecular por meio da técnica de PCR em tempo real não detectou nas amostras de tecidos de ovinos comercializados em mercados públicos de Feira de Santana a presença de DNA compatível com os controles utilizados, entretanto, ocorreu à amplificação de uma amostra que será sequenciada para determinação da espécie. A sequência amplificada será submetida ao sequenciamento para determinação do microrganismo envolvido. $O$ kit de extração A foi mais eficiente na extração de DNA das amostras de tecidos, com médias de

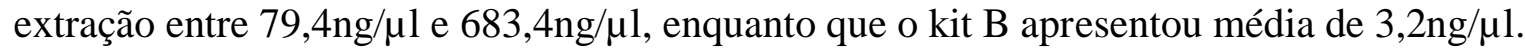

\section{REFERÊNCIAS}

ALFONSO, Y. et al. 2009. Detection of Toxoplasma gondii in cerebrospinal fluid from AIDS patients by nested PCR and rapid identification of type I allele at B1 gene by RFLP analysis. Experimental Parasitology 122 (3): 203-207.

BUXTON, D. 1998. Protozoan infections (Toxoplasma gondii, Neospora caninum and Sarcocystis spp.) in sheep and goats: recent advances. Veterinary Research 29 (3): 289-310.

CENCI-GOGA, B. T. et al. 2011. Toxoplasma in animals, food, and humans: an old parasite of new concern. Foodborne Pathogens and Disease 8 (7): 751-762.

DEHAGHI, M. M. et al. 2013. Survey of Sarcocystis infection in slaughtered sheep in Kerman Abattoir, Kerman, Iran. Comparative Clinical Pathology 22 (3): 343-346. 
DUBEY, J. P. et al. 2005. Isolation, tissue distribution, and molecular characterization of Toxoplasma gondii from chickens in Grenada, West Indies. Journal of Parasitology 91 (3): 557-560.

FEHLBERG, H.F. 2016. Identificação e diferenciação dos protozoários Toxoplasma gondii, Sarcocystis neurona, Neospora caninum e Cryptosporidium parvum através da técnica de High Resolution Melting (HRM). Universidade Estadual de Santa Cruz, Dissertação.

FUKUYO, M.; BATTSETSEG, G.; BYAMBAA, B. 2002. Prevalence of Sarcocystis infection in meat-producing animals in Mongolia. Southeast Asian Journal of Tropical Medicine and Public Health 33 (3): 490-495.

GUTIERREZ, J. et al. 2010. Detection and quantification of Toxoplasma gondii in ovine maternal and foetal tissues from experimentally infected pregnant ewes using real-time PCR. Veterinary Parasitology 172 (1): 8-15.

JEROME, K. R. et al. 2002. Quantitative stability of DNA after extended storage of clinical specimens as determined by real-time PCR. Journal of Clinical Microbiology 40 (7): 26092611.

JURÁNKOVÁ, J. et al. 2015. Predilection sites for Toxoplasma gondii in sheep tissues revealed by magnetic capture and real-time PCR detection. Food Microbiology 52, 150-153.

LALONDE, L. F.; GAJADHAR, A. A. 2011. Detection and differentiation of coccidian oocysts by real-time PCR and melting curve analysis. Journal of Parasitology 97(4): 725-730. KOLENDA, R.; UGORSKI, M.; BEDNARSKI, M. 2014. Molecular characterization or Sarcocystis species from Polish roe deer based on ssu rRNA and cox1 sequence analysis. Parasitology Research 113 (8): 3029-3039.

MUGRIDGE, N. B.; MORRISON, D. A.; JOHNSON, A. M, et al. 1999. Phylogenetic relationships of the genus Frenkelia: a review of its history and new knowledge gained from comparison of large subunit ribosomal ribonucleic acid gene sequences. International Journal for Parasitology 29 (6): 957-972.

PIERGILI, F. D. 2004. [Problems and limitations of conventional and innovative methods for the diagnosis of Toxoplasmosis in humans and animals]. Parassitologia 46 (1-2): 177-181.

PORTELLA, L. P. et al. 2016. Molecular detection of protozoa of the Sarcocystidae family in sheep from the State of Rio Grande do Sul, Brazil. Ciência Rural 46 (9): 1613-1617.

REY, L. 2001. Parasitologia. Rio de Janeiro, Guanabara Koogan, 856p.

RASSOULI, M.; AHMADPANAHI, J.; ALVANDI, A. 2014. Prevalence of Sarcocystis spp. and Hammondia spp. microcysts in esophagus tissue of sheep and cattle, emphasized on their morphological differences. Parasitology Research 103 (10): 3801-3805.

SILVA, A. F.; BRANDÃO, F. Z.; FERREIRA, A. M. R. 2013. Neospore ovina: estado da arte. Revista Brasileira Reprodução Animal 37 (1): 45-52.

SWITAJ, K.; MASTER, A.; SKRZYPCZAK, M.; ZABOROWSKI, P. 2005. Recent trends in molecular diagnostics for Toxoplasma gondii infections. Clinical Microbiology and Infection 11 (3): 170-176.

TAIRA, K.; SAITOH, Y.; KAPEL, C. M. O. 2011. Toxocara cati larvae persist and retain high in muscles of experimentally infected chickens. Veterinary Parasitology 180 (3): 287291.

VALONES, M. A. A. et al. 2009. Principles and applications of polymerase chain reaction in medical diagnostic fields: a review. Brazilian Journal of Microbiology 40 (1): 1-11.

VARMA, M. et al. 2003. Detection of Cyclospora cayetanensis using a quantitative real-time PCR assay. Journal of Microbiological Methods, 53 (1): 27-36. 